\title{
KAJIAN AWAL PERENCANAAN LENTUR JEMBATAN LALU LINTAS RINGAN MENGGUNAKAN GELAGAR FERRO FOAM CONCRETE
}

\author{
Syarifah Asria Nanda \\ Jurusan Teknik Sipil Universitas Malikussaleh \\ syarifah_nanda@yahoo.com
}

\begin{abstract}
Abstrak
Umumnya gelagar terbuat dari beton bertulang yang relatif berat, yang dalam pelaksanaannya membutuhkan cetakan (bekisting) dan penyokong yang relatif banyak untuk menahan beban selama pelaksanaan. Untuk mengatasi hal ini digunakan material ferro foam concrete dengan bentuk profil I sebagai gelagar. Tujuan penelitian ini adalah mengetahui besarnya kapasitas daya dukung yang timbul berdasarkan variasi tinggi gelagar untuk bentang-bentang pendek. Variasi tinggi gelagar yang ditinjau adalah $150 \mathrm{~mm}, 200 \mathrm{~mm}$ dan 300 $\mathrm{mm}$. Bentang-bentang yang akan ditinjau yaitu 1,5 meter, 2 meter, 2,5 meter, 3 meter, 3,5 meter, 4 meter, 5 meter, dan 6 meter. Hasil penelitian menunjukkan bahwa momen nominal lebih besar dari momen ultimit untuk panjang bentang maksimum 2 meter pada tipe jembatan lalu lintas ringan. Sedangkan pada jembatan pedestrian menunjukkan bahwa momen nominal lebih besar dari momen ultimit untuk panjang bentang maksimum 5 meter. Nilai momen nominal tahanan (ФMn) untuk gelagar ukuran $15 \times 20 \mathrm{~cm}$ diperoleh $\Phi$ Mn sebesar 1,1 ton, ukuran 20x20 cm diperoleh ФMn sebesar 1.6 ton, dan ukuran 30x20 cm diperoleh $\Phi$ Mn sebesar 2.8 ton. Besar dimensi gelagar juga mempengaruhi besarnya lendutan, semakin tinggi gelagar maka semakin kecil lendutannya.
\end{abstract}

Kata Kunci: Profil I, ferro foam concrete

\section{Pendahuluan}

Pembangunan saranan dan prasarana transportasi sangat menunjang tercapainya program pembangunan yang sudah direncanakan. Dengan adanya prasarana jalan dan jembatan yang memadai akan berdampak baik di bidang sosial, ekonomi, politik dan hankam baik secara lokal, regional maupun secara nasional. Jembatan sebagai infrastruktur transportasi, mempunyai peran utama dalam sistem jaringan jalan dan sangat berpengaruh terhadap kelancaran transportasi. Jembatan digunakan sebagai penghubung dua bagian jalan yang terputus oleh adanya rintangan-rintangan seperti alur sungai, lembah, danau, saluran irigasi, jalan kereta api, jalan raya yang melintang tidak sebidang dan lainlain.

Di daerah pedesaan banyak dijumpai jembatan yang sudah rusak dan tidak layak untuk digunakan lagi sebagai sarana transportasi. Dalam hal ini, usaha yang harus dilakukan pemerintah adalah dengan memperbaiki jembatan atau membangun jembatan yang baru sehingga tercipta jalur lalu lintas yang nyaman, aman dan efisien. Jembatan pedesaan biasanya menggunakan material kayu, karena kayu merupakan material yang mudah diperoleh dan mudah pemasangannya di lapangan, namun penggunaannya sudah dibatasi sejak pemerintah mengeluarkan UU No. 41/1999 tentang Illegal Logging karena penebangan pohon dapat berdampak buruk terhadap lingkungan. 
Ferro foam concrete merupakan material beton ringan yang menyerupai ferosemen, dengan menganti mortar pada ferosemen dengan material foam concrete (beton busa). Dari hasil penelitian-penelitian sebelumnya disimpulkan bahwa ferro foam concrete dapat digunakan sebagai alternatif material untuk gelagar jembatan bentang pendek.

Kajian awal perlu dilakukan untuk mengetahui besarnya kapasitas daya dukung yang timbul berdasarkan variasi tinggi gelagar untuk bentang-bentang pendek. Hal ini dilakukan agar memudahkan para perencana dalam mendesain jembatan dengan mengetahui pola ulang gelagar sesuai dengan panjang bentang yang dibutuhkan.

\section{Tinjauan Kepustakaan}

Ferro foam concrete merupakan material yang dimodifikasi dari material ferosemen. Prinsip dasar dari material ferro foam concrete adalah dengan mengganti bahan mortar pada ferosemen dengan bahan foam concrete (beton busa (Nazliza, 2013).

Pada Ferro foam concrete sama seperti pada ferosemen diberi tulangan jaringan kawat yang relatif kecil diameternya dan tersebar merata dalam beberapa lapisan. Tulangan jaringan kawat tersebut adalah tulangan kawat baja atau bahan lain yang sesuai kebutuhan. Karakteristik jaringan kawat dapat dilihat pada Gambar berikut. (Naaman, $2000: 25$ )

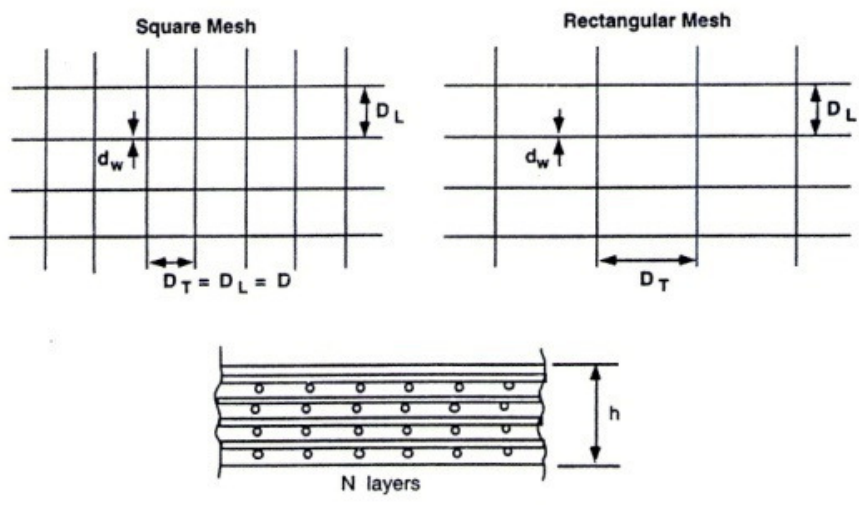

Gambar 1 Jaring Kawat

Gambar 1 merupakan jaring kawat di mana $\mathrm{d}_{\mathrm{w}}$ adalah diameter kawat $(\mathrm{mm}), \mathrm{D}_{\mathrm{L}}$ adalah jarak pusat ke pusat kawat (p.k.p) dalam arah memanjang $(\mathrm{mm}), \mathrm{D}_{\mathrm{T}}$ adalah jarak pusat ke pusat kawat (p.k.p) dalam arah melintang $(\mathrm{mm}), \mathrm{N}$ adalah jumlah lapisan jaring kawat (wire mesh) dan h adalah tinggi elemen (mm).

Beton Busa memiliki beberapa kelebihan dibandingkan Beton konvensional, yaitu :

1. Keunggulan beton terletak pada berat yang lebih ringan dari beton konvensional berkisar $600-1600 \mathrm{~kg} / \mathrm{m}^{3}$, sehingga dapat mengurangi berat sendiri bangunan. 
2. Bobot yang ringan dapat mengurangi biaya transportasi.

3. Memudahkan tukang dalam pengerjaan bangunan karena bobotnya yang ringan tersebut.

4. Meminimalisir jumlah tukang sehingga secara keseluruhan bisa lebih murah dan efisien.

5. Waktu pembangunan lebih pendek.

6. Tahan panas dan api, karena berat jenisnya rendah.

7. Kedap suara.

Beton Busa memiliki kelemahan dibandingkan Beton Konvensional, yaitu memiliki kuat lekat (born strengh) lebih rendah dari beton normal. Menurut Naaman (2000:154), rumus untuk menghitung lendutan dengan tumpuan sederhana ialah :

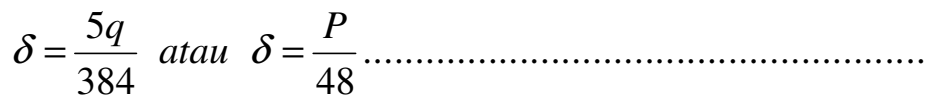

Lendutan maksimum 1/240L untuk balok pendukung lantai beton bertulang (PBBI 1971: 108).

di mana :

$$
\begin{aligned}
& \mathrm{P}=\text { Beban } \\
& \mathrm{q}=\text { Beban Merata } \\
& \mathrm{L}=\text { Panjang Bentang } \\
& \mathrm{Ec}=\text { Modulus Elastisitas Beton }
\end{aligned}
$$

Menurut Naaman (2000:138), momen nominal tahanan dihitung dengan rumus:

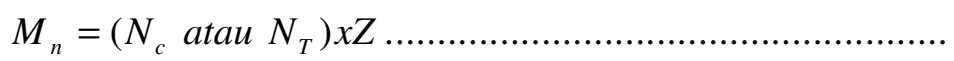

di mana:

$\mathrm{Mn}=$ Momen nominal tahanan

$\mathrm{N}_{\mathrm{C}}=$ Gaya tekan pada beton

$\mathrm{N}_{\mathrm{T}}=$ Gaya tarik pada tulangan

$\mathrm{Z}$ = Jarak antara gaya tekan dengan gaya tarik

Menurut RSNI T12-2004, modulus elastisitas beton ringan yang kuat tekannya lebih kecil dari $40 \mathrm{MPa}$ dan berat volume beton tidak kurang dari 2000 $\mathrm{kg} / \mathrm{m}^{3}$ dapat di ambil sebesar:

$$
E_{C}=W_{C}^{1.5}(0,043 \sqrt{f})
$$

di mana:

$$
\begin{aligned}
& \mathrm{Ec}=\text { Modulus elastisitas beton ringan }(\mathrm{MPa}) \\
& \mathrm{Wc}=\text { Berat volume beton ringan }\left(\mathrm{kg} / \mathrm{m}^{3}\right) \\
& \mathrm{fc}^{\prime}=\text { Kuat tekan beton ringan }(\mathrm{MPa})
\end{aligned}
$$

Menurut peraturan pemerintah no. 43/1993, kelas jalan dapat dibagi menjadi jalan Arteri (klas I,II,IIIA), jalan Kolektor (IIIA dan IIIB), jalan Lokal (IIIC). Pada penelitian ini, jembatan yang ditinjau termasuk kedalam jalan klas IIIC dengan lebar lajur ideal $3 \mathrm{~m}$. 
Pembebanan dan aksi-aksi lainnya yang digunakan dalam perencanaan jembatan jalan raya menurut RSNI T-02-2005 (standar pembebanan untuk jembatan), dan BMS (Bridge Management System) dapat dikelompokkan sebagai berikut : Aksi dan beban tetap dan aksi lalu lintas dan aksi lingkungan.

\section{Metode Penelitian}

Perencanaan dilakukan secara manual dengan menggunakan perangkat keras dan perangkat lunak. Perangkat keras (hardware) digunakan sebagai media bagi perangkat lunak (software). Perangkat lunak yang digunakan yaitu Microsoft Office Excel 2007.

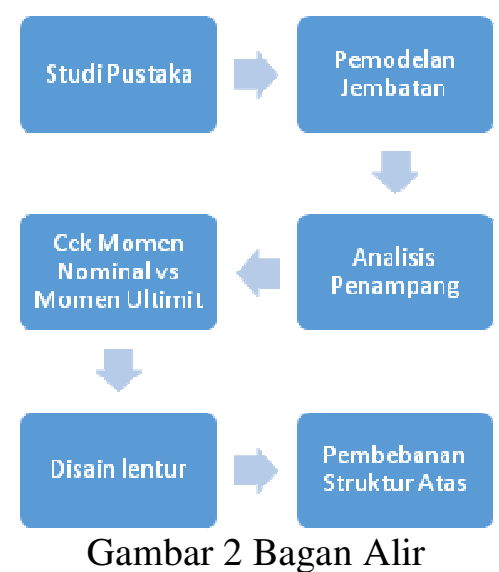

\subsection{Data Perencanaan}

Langkah pertama dalam penelitian ini adalah menentukan data perencanaan yang merupakan spesifikasi jembatan. Adapun data perencanaan pada penelitian ini adalah sebagai berikut:

- Jenis jembatan: jembatan ferro foam concrete

- Panjang bentang: 1,5 sampai 6 meter

- Klasifikasi jalan: lokal (kelas IIIC) atau pedesaan

- Lebar jembatan: $3 \mathrm{~m}$ (tanpa trotoar)

- Plat lantai kendaraan: beton ferro foam bentuk kanal yang disusun sebagai profil U merupakan gabungan precast dengan cast in place, ukuran $15 \times 20 \mathrm{x}$ $200 \mathrm{~cm}$, tebal profil $40 \mathrm{~mm}$, dengan $\mathrm{f}_{\mathrm{c}}{ }^{\prime}=30 \mathrm{MPa}, \mathrm{f}_{\mathrm{y}}=410 \mathrm{MPa}$ baja ulir D8, $\mathrm{f}_{\mathrm{y}}$ $=420 \mathrm{MPa}$ jaring kawat

- Gelagar memanjang: ferro foam concrete berbentuk kanal dikonfigurasi menjadi profil I dengan ukuran $15 \times 20 \times 200 \mathrm{~cm}, 20 \times 20 \times 200 \mathrm{~cm}$ dan $30 \times$ $20 \times 200 \mathrm{~cm}$ dengan tebal profil $30 \mathrm{~mm}, \mathrm{f}_{\mathrm{c}}{ }^{\prime}=30 \mathrm{MPa}, \mathrm{f}_{\mathrm{y}}=422 \mathrm{MPa}$ baja ulir $\mathrm{D} 8, \mathrm{f}_{\mathrm{y}}=420 \mathrm{MPa}$ jaring kawat

- Sandaran: mendatar dari baja CPN-4 dan tiang sandaran dari baja CPN-12, tinggi tiang sandaran $90 \mathrm{~cm}$ dan jarak antara tiang $100 \mathrm{~cm}$

\subsection{Pemodelan Jembatan}

Langkah kedua pada penelitian ini adalah menentukan model dari struktur jembatan yang akan ditinjau beserta komponen-komponennya. Gambar keseluruhan jembatan dalam arah melintang dapat dilihat pada Gambar 3. 
Bagian komponen jembatan yang ditinjau yaitu gelagar memanjang bentuk kanal yang dikonfigurasikan menjadi profil I yang disusun dengan jarak antara gelagar $50 \mathrm{~cm}$.

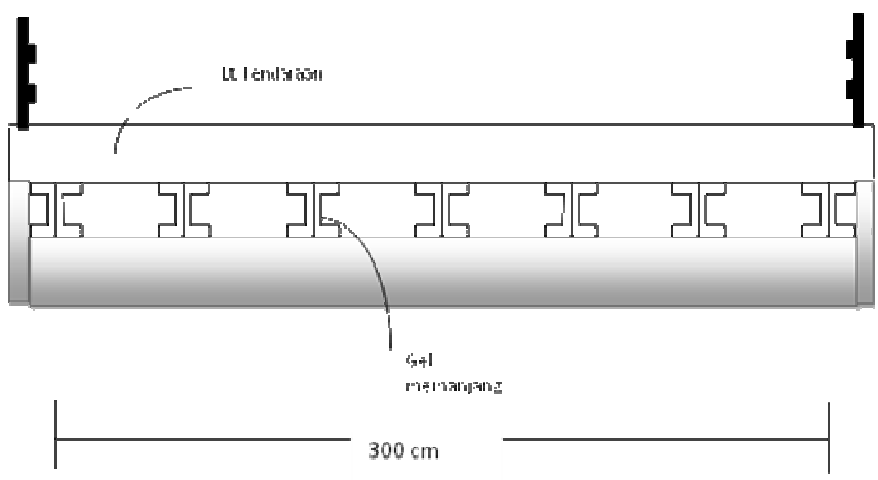

Gambar 3 Pemodelan Jembatan

\subsection{Analisis Penampang}

Langkah ketiga pada penelitian ini adalah menentukan dimensi gelagar memanjang yang tediri dari tiga variasi tinggi gelagar, yaitu $15 \mathrm{~cm}, 20 \mathrm{~cm}$ dan 30 $\mathrm{cm}$. Selanjutnya menganalisis gelagar tersebut sehingga diperoleh nilai Momen Inersia Penampang dan Momen Nominal Tahanan dari ketiga profil. Ketiga profil ini akan dipakai untuk jembatan dengan beberapa panjang bentang, yaitu 1,5 meter, 2 meter, 1,5 meter, 3 meter, 3,5 meter, 4 meter, 5 dan 6 meter, dengan tipe jembatan adalah jembatan lalu lintas ringan. Variasi Profil untuk setiap bentang dapat diperlihatkan pada Tabel 1.

Tabel 1 Variasi Profil Gelagar

\begin{tabular}{|c|c|c|c|}
\hline $\begin{array}{c}\text { Bentang } \\
\text { (meter) }\end{array}$ & Dimensi & Bentang (meter) & Dimensi \\
\hline $\mathbf{1 , 5}$ & $\begin{array}{c}15 \times 20 \times 200 \mathrm{~cm} \\
20 \times 20 \times 200 \mathrm{~cm}\end{array}$ & 3,5 & $15 \times 20 \times 200 \mathrm{~cm}$ \\
& $30 \times 20 \times 200 \mathrm{~cm}$ & & $\begin{array}{l}20 \times 20 \times 200 \mathrm{~cm} \\
30 \times 20 \times 200 \mathrm{~cm}\end{array}$ \\
\hline $\mathbf{2}$ & $15 \times 20 \times 200 \mathrm{~cm}$ & 4 & $15 \times 20 \times 200 \mathrm{~cm}$ \\
& $20 \times 20 \times 200 \mathrm{~cm}$ & & $20 \times 20 \times 200 \mathrm{~cm}$ \\
& $30 \times 20 \times 200 \mathrm{~cm}$ & & $30 \times 20 \times 200 \mathrm{~cm}$ \\
\hline $\mathbf{2 , 5}$ & $15 \times 20 \times 200 \mathrm{~cm}$ & 5 & $15 \times 20 \times 200 \mathrm{~cm}$ \\
& $20 \times 20 \times 200 \mathrm{~cm}$ & & $20 \times 20 \times 200 \mathrm{~cm}$ \\
& $30 \times 20 \times 200 \mathrm{~cm}$ & & $30 \times 20 \times 200 \mathrm{~cm}$ \\
\hline $\mathbf{3}$ & $15 \times 20 \times 200 \mathrm{~cm}$ & 6 & $15 \times 20 \times 200 \mathrm{~cm}$ \\
& $20 \times 20 \times 200 \mathrm{~cm}$ & & $20 \times 20 \times 200 \mathrm{~cm}$ \\
& $30 \times 20 \times 200 \mathrm{~cm}$ & & $30 \times 20 \times 200 \mathrm{~cm}$ \\
\hline
\end{tabular}

Penampang gelagar ferro foam concrete bentuk kanal konfigurasi I dengan dimensi paling kecil adalah 15 × 20 x $200 \mathrm{~cm}$ dengan tebal profil $30 \mathrm{~mm}$, dapat dilihat pada Gambar 4. 


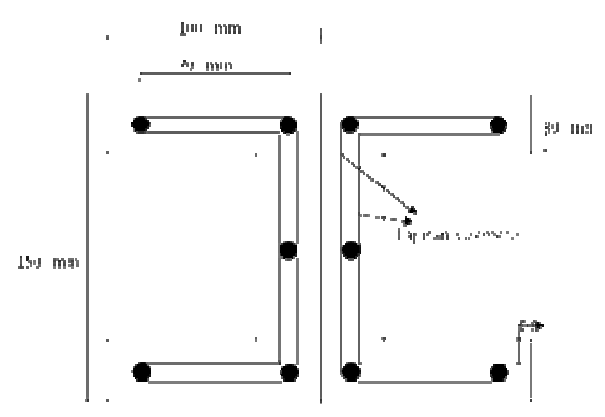

\section{Gambar 4 Penampang Gelagar I}

\subsection{Pembebanan Struktur Atas Jembatan}

Beban yang dianalisa pada struktur jembatan ini merupakan beban statik, yang dianalisis berdasarkan standar pembebanan jembatan sesuai dengan peraturan RSNI atau BMS, dengan menentukan beban mati, beban hidup, dan beban angin. Metode perencanaan struktur jembatan yang digunakan adalah metode perencanaan ultimit (Load Resistant Factor Design, LRFD).

Analisis beban dimulai dengan menghitung lantai kendaraan dan sandaran jembatan, kemudian baru dilanjutkan dengan menghitung gelagar memanjang. Perhitungan dilakukan secara manual dengan menggunakan Microsoft Office Excel 2007.

Pembebanan lantai kendaraan untuk jembatan kelas IIIC meliputi beban mati. Beban mati lantai kendaraan meliputi berat lantai sendiri, berat aspal dan berat air hujan.

Pembebanan Gelagar Memanjang meliputi:

- Berat Mati

Berat mati merupakan berat sendiri gelagar memanjang dan berat plat lantai.

- Beban Mati Tambahan

Beban mati tambahan merupakan berat aspal setebal $50 \mathrm{~mm}$ dan genangan air hujan setinggi $50 \mathrm{~mm}$.

- Beban Hidup "T"

Untuk jembatan lalu lintas ringan diperhitungkan beban hidup bergerak berupa kendaraan ringan. Beban hidup untuk jembatan klas IIIC diganti dengan mobil pick up yang tergolong kendaraan ringan dan memiliki berat maksimum 3 ton. Muatan sumbu diambil 50\% dari muatan berat maksimum yaitu masing-masing 1,5 ton roda depan dan roda belakang.

- Beban Angin

Diambil dari perhitungan beban angin pada lantai kendaraan.

Momen ultimit gelagar jembatan yang terjadi ditengah bentang harus lebih kecil dari momen nominal tahanan, sehingga konstruksi menjadi aman. Momen nominal tahanan telah didapat dari hasil perhitungan pendimensian gelagar.

$\mathrm{Mu} \leq \Phi M n$ dengan faktor tahanan untuk struktur menahan lentur diasumsikam $\Phi=0,80$ 


\section{Hasil dan Pembahasan}

Hasil yang diperoleh dari penelitian ini meliputi momen ultimit, momen tahanan, dan lendutan, untuk 8 variasi bentang dengan 3 variasi tinggi gelagar foam concrete. Jenis jembatan yaitu jembatan lalu lintas ringan.

Momen nominal tahanan setelah dikalikan faktor reduksi 0,8 untuk ketiga variasi tinggi gelagar yaitu 1,1 tm untuk H15, 1,6 tm untuk $\mathrm{H} 20$ dan 2,8 tm untuk H30. Momen nominal penampang terbesar terjadi pada profil dengan tinggi 30 $\mathrm{cm}$, yaitu $2,8 \mathrm{tm}$. Semakin tinggi profil maka nilai dari momen nominal tahanan menjadi semakin besar.

Tabel 2 Momen Nominal Tahanan

\begin{tabular}{|c|c|c|c|}
\hline SIMBOL & Dimensi & $\begin{array}{c}\text { Mn } \\
(\mathbf{t m})\end{array}$ & $\begin{array}{c}\boldsymbol{\Phi M n} \\
(\mathbf{t m})\end{array}$ \\
\hline H15 & $15 \times 20 \times 200$ & 1,3 & 1,1 \\
\hline H20 & $20 \times 20 \times 200$ & 2,0 & 1,6 \\
\hline H30 & $30 \times 20 \times 200$ & 3,5 & 2,8 \\
\hline
\end{tabular}

Data hasil perhitungan maka besar momen ultimit seperti diperlihatkan pada Tabel 3.

Tabel 3 Nilai Momen Ultimit Jembatan Lalu Lintas Ringan

\begin{tabular}{|c|c|c|c|c|c|}
\hline $\begin{array}{l}\text { Bentang } \\
\text { (meter) }\end{array}$ & $\begin{array}{l}\text { Dimensi } \\
\mathrm{cm}\end{array}$ & Mu (tm) & $\begin{array}{c}\text { Bentang } \\
\text { (meter) }\end{array}$ & $\begin{array}{c}\text { Dimensi } \\
\mathrm{cm}\end{array}$ & $\mathbf{M u}(\mathbf{t m})$ \\
\hline 1,5 & $\begin{array}{l}15 \times 20 \times 200 \\
20 \times 20 \times 200 \\
30 \times 20 \times 200\end{array}$ & $\begin{array}{l}1.675 \\
1.677 \\
1.681\end{array}$ & 3,5 & $\begin{array}{l}15 \times 20 \times 200 \\
20 \times 20 \times 200 \\
30 \times 20 \times 200\end{array}$ & $\begin{array}{l}4.219 \\
4.230 \\
4.252\end{array}$ \\
\hline 2 & $\begin{array}{l}15 \times 20 \times 200 \\
20 \times 20 \times 200 \\
30 \times 20 \times 200\end{array}$ & $\begin{array}{l}2.277 \\
2.281 \\
2.288\end{array}$ & 4 & $\begin{array}{l}15 \times 20 \times 200 \\
20 \times 20 \times 200 \\
30 \times 20 \times 200\end{array}$ & $\begin{array}{l}4.911 \\
4.925 \\
4.953\end{array}$ \\
\hline 2,5 & $\begin{array}{l}15 \times 20 \times 200 \\
20 \times 20 \times 200 \\
30 \times 20 \times 200\end{array}$ & $\begin{array}{l}2.902 \\
2.908 \\
2.919\end{array}$ & 5 & $\begin{array}{l}15 \times 20 \times 200 \\
20 \times 20 \times 200 \\
30 \times 20 \times 200\end{array}$ & $\begin{array}{l}7.411 \\
7.433 \\
7.477\end{array}$ \\
\hline 3 & $\begin{array}{l}15 \times 20 \times 200 \\
20 \times 20 \times 200 \\
30 \times 20 \times 200\end{array}$ & $\begin{array}{l}3.550 \\
3.558 \\
3.574\end{array}$ & 6 & $\begin{array}{l}15 \times 20 \times 200 \\
20 \times 20 \times 200 \\
30 \times 20 \times 200\end{array}$ & $\begin{array}{l}10.000 \\
10.032 \\
10.096\end{array}$ \\
\hline
\end{tabular}

Hubungan momen dengan panjang bentang untuk jembatan lalu lintas ringan diperlihatkan pada Gambar 5. 


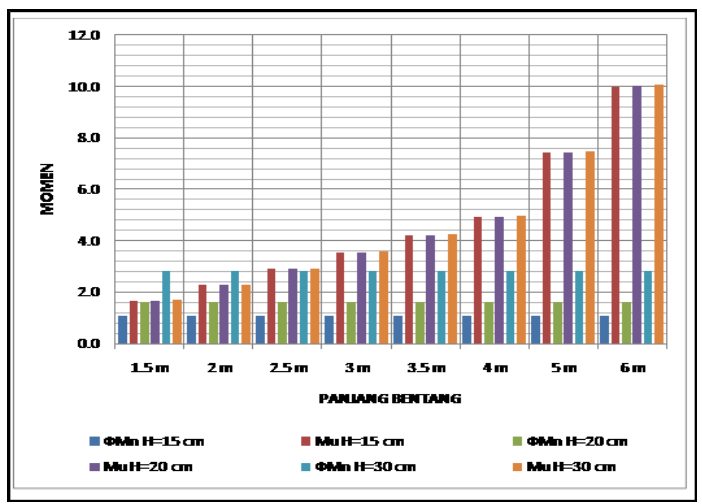

Gambar 5 Hubungan Momen dengan Panjang Bentang untuk Jembatan Lalu Lintas Ringan

Pada penelitian ini nilai lendutan yang timbul pada setiap variasi panjang bentang yang diperoleh dari perhitungan lendutan dapat dilihat pada Tabel 4 untuk Jembatan Lalu lintas Ringan.

\begin{tabular}{|c|c|c|c|c|}
\hline $\begin{array}{c}\text { Panjang } \\
\text { Bentang } \\
\text { (m) }\end{array}$ & $\begin{array}{l}\text { Smax } \\
(\mathbf{m m})\end{array}$ & $\begin{array}{c}\delta \\
\text { H15 } \\
(\mathrm{mm})\end{array}$ & $\begin{array}{c}\delta \\
\text { H20 } \\
(\mathbf{m m})\end{array}$ & $\begin{array}{c}\delta \\
\text { H30 } \\
(\mathbf{m m})\end{array}$ \\
\hline 1.5 & 6.25 & 3.54 & 1.67 & 0.58 \\
\hline 2 & 8.33 & 8.67 & 4.10 & 1.43 \\
\hline 2.5 & 10.42 & 17.47 & 8.26 & 2.89 \\
\hline 3 & 12.50 & 31.12 & 14.72 & 5.17 \\
\hline 3.5 & 14.58 & 50.88 & 24.09 & 8.46 \\
\hline 4 & 16.67 & 78.15 & 37.01 & 13.02 \\
\hline 5 & 20.83 & 161.20 & 76.43 & 26.93 \\
\hline 6 & 25.00 & 293.38 & 139.21 & 49.13 \\
\hline
\end{tabular}

Lendutan yang terjadi akan bertambah besar dengan adanya penambahan panjang bentang, Pada jembatan lalu lintas ringan, lendutan maksimum terjadi pada bentang $6 \mathrm{~m}$ dengan tinggi gelagar $15 \mathrm{~cm}$ yaitu sebesar 293,38 mm. Lendutan terkecil terjadi pada bentang $1,5 \mathrm{~m}$ dengan tinggi gelagar $30 \mathrm{~m}$ yaitu sebesar $0,58 \mathrm{~mm}$.

Besar dimensi gelagar juga mempengaruhi besarnya lendutan, semakin tinggi gelagar maka semakin kecil lendutannya. Artinya semakin besar dimensi gelagar dapat mengurangi besar lendutan dari gelagar. 


\section{Kesimpulan dan Saran}

\subsection{Kesimpulan}

Berdasarkan hasil analisis dari data yang telah dilakukan, maka dapat disimpulkan:

1. Momen nominal tahanan yang mampu ditahan oleh gelagar dengan variasi tinggi $15 \mathrm{~cm}, 20 \mathrm{~cm}$ dan $30 \mathrm{~cm}$ berturut-turut sebagai berikut adalah 1,1 tm, 1,6 $\mathrm{tm}$, dan 2,8 tm. Semakin tinggi dimensi gelagar semakin besar pula nilai momen tahanannya.

2. Untuk jembatan lalu lintas, profil dengan tinggi $15 \mathrm{~cm}$ dan $20 \mathrm{~cm}$ tidak aman digunakan untuk kedelapan bentang. Profil dengan tinggi $30 \mathrm{~cm}$ aman digunakan untuk panjang bentang 1,5 meter dan 2 meter. Untuk panjang bentang lebih dari 2 meter tidak dapat digunakan ketiga profil.

3. Dari hasil penelitian jenis bahan ferro foam concrete ini, dapat dipakai sebagai gelagar jembatan lalu lintas ringan.

\subsection{Saran}

Penelitian ini diharapkan dapat dilanjutkan oleh peneliti lain, dengan memperhatikan beberapa hal dan saran sebagai berikut:

1. Untuk meningkakan kapasitas lentur dapat dilakukan dengan menaikan mutu material baik beton maupun baja tulangan serta kawat jaring.

2. Mengubah dimensi gelagar dan dapat juga dengan mengubah bentuk profil menjadi persegi.

3. Meninjau lebih lanjut terhadap kapasitas gesernya

\section{Daftar Kepustakaan}

AASHTO, 1998, AASHTO LRFD Bridge Design Spesifications, SI unit $2^{\text {nd }}$ edition, American Association of State Highway and Transportation Offcials, Washington, D.C

AASHTO, 1998, AASHTO LRFD Bridge Design Spesifications, SI unit $4^{\text {th }}$ edition, American Association of State Highway and Transportation Offcials, Washington, D.C

AASHTO, 1996, Standar Spesifications for Highway Bridges, 16 $^{\text {th }}$ edition, American Association of State Highway and Transportation Offcials, Washington, D.C

Anonim, 1992, Peraturan Perencanaan Teknik Jembatan, Bridge Management System, Departemen Pekerjaan Umum Direktorat Jenderal Bina Marga, Direktorat Bina Program Jalan, Bandung

Anonim, RSNI T-12-2004, Perencanaan Struktur Beton Untuk Jembatan, Departemen Pekerjaan Umum Anonim, RSNI T-02- 2005, Standar Pembebanan untuk Jembatan, Departemen Pekerjaan Umum

Demetrios E. Tonias, P.E dan Jim J. Zhao, P.E, 2007, Bridge Engineering, Second edition, McGraw-Hill, New York.

Dipohusodo, I., 1993, Struktur Beton Bertulang, PT Gramedia Pustaka Utama, Jakarta. 
Masri,M., 2015, Perilaku Lentur Pelat Lantai Gabungan Beton Precast da Cast In Place Beton Busa dengan Penambahan Shear Connector pada Bidang Interface Akibat Beban Terpusat, Universitas Syiah Kuala.

Naaman,A.E., 2000, Ferrocement and Laminated Cementitious Composites, Techno Press 3000, Michigan

Nazliza, 2013, Perilaku Balok Profil Kanal Ferro Foam Concrete dengan Penambahan Pozzolan Alami Akibat Beban Lentur, Universitas Syiah Kuala.

Richard M. Barker dan Jay A. Pucket, 2007, Design of Highway Bridges LRFD Approach, second edition, John Wiley \& Sons. Inc, New Jersey.

Tyler G. dan Hicks, P.E., 2002, Civil Engineering Formulas, McGraw-Hill, New York. 